\title{
Comparison of indoor and outdoor fungi and particles in poultry units
}

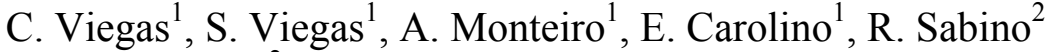 \\ \& C. Veríssimo ${ }^{2}$ \\ ${ }^{1}$ Higher School of Health Technologies of Lisbon, \\ Polytechnic Institute of Lisbon, Portugal \\ ${ }^{2}$ National Institute of Health Dr. Ricardo Jorge, \\ Mycology Laboratory, Portugal
}

\begin{abstract}
A descriptive study was developed in order to compare indoor and outdoor air contamination caused by fungi and particles in seven poultry units. Twenty eight air samples of 25 litters were collected through the impaction method on malt extract agar. Air sampling and particles concentration measurement were done in the interior and also outside premises of the poultries' pavilions.

Regarding the fungal load in the air, indoor concentration of mold was higher than outside air in six poultry units. Twenty eight species / genera of fungi were identified indoor, being Scopulariopsis brevicaulis (40.5\%) the most commonly isolated species and Rhizopus sp. (30.0\%) the most commonly isolated genus.

Concerning outdoor, eighteen species/genera of fungi were isolated, being Scopulariopsis brevicaulis (62.6\%) also the most isolated. All the poultry farms analyzed presented indoor fungi different from the ones identified outdoors.

Regarding particles' contamination, PM2.5, PM5.0 and PM10 had a statistically significant difference (Mann-Whitney U test) between the inside and outside of the pavilions, with the inside more contaminated ( $p=.006 ; p=.005$; $\mathrm{p}=.005$, respectively). The analyzed poultry units are potential reservoirs of substantial amounts of fungi and particles and could therefore free them in the atmospheric air. The developed study showed that indoor air was more contaminated than outdoors, and this can result in emission of potentially pathogenic fungi and particles via aerosols from poultry units to the environment, which may post a considerable risk to public health and contribute to environmental pollution.
\end{abstract}

Keywords: poultry, indoor, outdoor, fungi, particles. 


\section{Introduction}

Intensive poultry production, implying large densities of animals in small areas, is a significant source of air pollution which may constitute a considerable health hazard to the birds, farmers and those living in the proximity of the farm [1]. On the other hand, the spread of bioaerosols to the outside of animal housing may result in local or even more extensive environmental pollution [2].

Organic dust is composed by viable particulate matter (also called bioaerosols). Bioaerosols are comprised of airborne bacteria, fungi, viruses and their by-products, endotoxin and mycotoxin [3, 4] and also by non-viable particles, generated by such things as faeces, litter, feed, feather formation (which produces a high quantity of allergen dandruff).

Thus, dust in poultry houses carries an inherent respiratory risk. Generally, dust particles are removed by cough, mucociliary cleaning, fagocytosis or lymphatic transport, and will not necessarily reach the alveolar region. Respiratory particles are defined as having in average $4.0 \mu \mathrm{m}$ or less [5].

Airway inflammation caused by a non-allergic mechanism has been well documented in the literature as the major respiratory health problem of people working in animal confinement buildings with heavy dust exposure, especially in swine and poultry productions [5-10]. Hypersensitive lungs have been related to inhalation of mold spores [7].

Gathering temporal information about the quantity and the composition of bioaerosols is necessary to better understand the relationship between factors that influence them and the adverse health symptoms of both workers and animals [11]. Besides that, much less is known about the relationships between the indoor and outdoor biological pollution, as well as about the spreading of indoor bioaerosols in the surroundings of the farms.

Taking into consideration these concerns, the purpose of this research was to compare indoor and outdoor air contamination caused by fungi and particles in seven poultry units.

\section{Materials and methods}

A descriptive study was developed in order to compare indoor and outdoor air contamination caused by fungi and particles in seven poultry units. Seasonal sampling was conducted in the winter of 2011 and farms were accommodated to 10000 and 60000 broilers.

Twenty eight air samples of 25 litters were collected through the impaction method on malt extract agar. Air sampling and particles concentration measurement were done in the interior and also outside premises of the poultries' pavilions.

Indoor and outdoor air samples were collected at a height of one meter with a flow rate of $140 \mathrm{~L} /$ minute, onto malt extract agar (MEA) supplemented with the antibiotic chloramphenicol $(0.05 \%)$. After laboratory processing and incubation of the collected samples, quantitative (colony forming units $-\mathrm{cfu} / \mathrm{m}^{3}$ ) and qualitative results were obtained, with identification of the isolated fungal 
species. Whenever possible, filamentous fungi were identified to the species level, since adverse health effects vary according to fungal species within the same genera $[12,13]$. Identification of filamentous fungi was carried out by macroscopic and microscopic observations, using lactophenol blue stain and achieved through comparison of morphological characteristics listed in illustrated literature [13].

Concerning particles, besides measurement of their concentration, differentiation between size fractions was also performed (PM0.5; PM1.0; PM2.5; PM5.0; PM10) due to the importance in health studies, aiming to estimate dust penetration within the respiratory system and, consequently, their potential health effect. In each poultry unit several indoor measurements and one outdoors were performed. Measurements were performed with direct-reading equipment (Lighthouse, TSI).

Tables with frequency distribution of the isolated fungal species were made with the obtained indoor and outdoor data. Data analysis was performed with the statistical software SPSS 19.0 using the correlation analysis.

\section{Results}

\subsection{Fungal contamination}

Regarding the fungal load in the air, indoor concentration of moulds was higher than outside air in six poultry units. Concerning fungal load in indoor air from the seven poultry farms, the highest mean value obtained was $14350 \mathrm{cfu} / \mathrm{m}^{3}$ and the lowest was $706.6 \mathrm{cfu} / \mathrm{m}^{3}$ (Table 1).

Table 1: Quantification of the fungal air load in indoor and outdoor of the seven poultries studied.

\begin{tabular}{|c|c|c|}
\hline $\begin{array}{c}\text { Poultry } \\
\text { farm }\end{array}$ & $\begin{array}{c}\text { Indoor * } \\
\text { cfu/m }\end{array}$ & $\begin{array}{c}\text { Outdoor } \\
\mathbf{c f u} / \mathbf{m}^{\mathbf{3}}\end{array}$ \\
\hline 1 & 1603,3 & 880 \\
\hline 2 & 4040 & 4040 \\
\hline 3 & 1586.6 & 640 \\
\hline 4 & 706.6 & 320 \\
\hline 5 & 14350 & 1280 \\
\hline 6 & 2540 & 2000 \\
\hline 7 & 5320 & 2520 \\
\hline
\end{tabular}

* Mean values.

Twenty eight species/genera of fungi were identified indoor, being Scopulariopsis brevicaulis $(40.5 \%)$ the most commonly isolated species and Rhizopus sp. (30.0\%) the most commonly isolated genus.

Regarding outdoor, eighteen species/genera of fungi were isolated, being Scopulariopsis brevicaulis (62.6\%) also the most isolated (Table 2). 
Table 2: $\quad$ Most frequent fungi identified in indoor and outdoor air.

\begin{tabular}{|c|c|c|c|}
\hline Indoor & $\begin{array}{c}\text { Frequency } \\
(\%)\end{array}$ & Outdoor & $\begin{array}{c}\text { Frequency } \\
\text { (\%) }\end{array}$ \\
\hline & & & \\
Scopulariopsis brevicaulis & 40.5 & Scopulariopsis brevicaulis & 62.6 \\
Rhizopus sp. & 30.0 & Aspergillus flavus & 14.7 \\
Penicillium sp. & 10.1 & Aspergillus sp. & 6.4 \\
Aspergillus sp. & 9.7 & Penicillium sp. & 6.1 \\
Others & 9.7 & Others & 10.2 \\
& & & \\
\hline
\end{tabular}

All the poultry farms analyzed showed indoor fungi different from the ones identified outdoors.

\subsection{Particles measurement}

Concerning contamination by particles, the ones with larger size were detected in higher concentrations, indoor and outdoor, particularly PM5.0 (particles of dimension $5.0 \mu \mathrm{m}$ or less) and PM10 (particles of dimension $10 \mu \mathrm{m}$ or less). Results obtained from the seven poultry farms - indoor and outdoor are shown in Table III and IV, respectively.

Table 3: $\quad$ Median values for particles concentration in each size (indoor).

\begin{tabular}{|c|c|c|c|c|c|}
\cline { 2 - 6 } \multicolumn{1}{c|}{} & \multicolumn{5}{c|}{ Indoor results } \\
\hline $\begin{array}{c}\text { Poultry } \\
\text { Units }\end{array}$ & $\begin{array}{c}\text { PM0.5 } \\
\left(\mathrm{mg} / \mathrm{m}^{3}\right)\end{array}$ & $\begin{array}{c}\text { PM1.0 } \\
\left(\mathrm{mg} / \mathrm{m}^{3}\right)\end{array}$ & $\begin{array}{c}\text { PM2.5 } \\
\left(\mathrm{mg} / \mathrm{m}^{3}\right)\end{array}$ & $\begin{array}{c}\text { PM5.0 } \\
\left(\mathrm{mg} / \mathrm{m}^{3}\right)\end{array}$ & $\begin{array}{c}\text { PM10 } \\
\left(\mathrm{mg} / \mathrm{m}^{3}\right)\end{array}$ \\
\hline A & $3.4 \times 10^{-4}$ & $6.7 \times 10^{-4}$ & $59.3 \times 10^{-4}$ & $1.0 \times 10^{4}$ & $6.0 \times 10^{4}$ \\
\hline B & $9.4 \times 10^{-4}$ & $18.6 \times 10^{-4}$ & $82.8 \times 10^{-4}$ & $8.4 \times 10^{2}$ & $3.2 \times 10^{5}$ \\
\hline C & $6.8 \times 10^{-4}$ & $1.2 \times 10^{-3}$ & $7.4 \times 10^{-3}$ & $1.1 \times 10^{5}$ & $8.0 \times 10^{5}$ \\
\hline D & $2.7 \times 10^{-4}$ & $4.6 \times 10^{-4}$ & $1.9 \times 10^{-3}$ & $3.4 \times 10^{-2}$ & $2.1 \times 10^{5}$ \\
\hline E & $1.4 \times 10^{-3}$ & $3.1 \times 10^{-3}$ & $21.6 \times 10^{-3}$ & $2.1 \times 10^{5}$ & $5.8 \times 10^{5}$ \\
\hline F & $2.3 \times 10^{-3}$ & $2.8 \times 10^{-3}$ & $7.9 \times 10^{-3}$ & $6.5 \times 10^{-2}$ & $2.6 \times 10^{5}$ \\
\hline G & $5.0 \times 10^{-4}$ & $7.5 \times 10^{-4}$ & $2.3 \times 10^{-3}$ & $2.2 \times 10^{-2}$ & $1.4 \times 10^{5}$ \\
\hline
\end{tabular}

Table 4: $\quad$ Results for particles concentration in each size (outdoor).

\begin{tabular}{|c|c|c|c|c|c|}
\hline & \multicolumn{5}{|c|}{ Outdoor results } \\
\hline $\begin{array}{l}\text { Poultry } \\
\text { Units }\end{array}$ & $\begin{array}{l}\text { PM0.5 } \\
\left(\mathrm{mg} / \mathrm{m}^{3}\right)\end{array}$ & $\begin{array}{l}\text { PM1.0 } \\
\left(\mathrm{mg} / \mathrm{m}^{3}\right)\end{array}$ & $\begin{array}{c}\text { PM2.5 } \\
\left(\mathrm{mg} / \mathrm{m}^{3}\right)\end{array}$ & $\begin{array}{c}\text { PM5.0 } \\
\left(\mathrm{mg} / \mathrm{m}^{3}\right)\end{array}$ & $\begin{array}{c}\text { PM10 } \\
\left(\mathrm{mg} / \mathrm{m}^{3}\right)\end{array}$ \\
\hline $\mathrm{A}$ & $3.54 \times 10^{-4}$ & $5.73 \times 10^{-4}$ & $16.17 \times 10^{-4}$ & $169.66 \times 10^{-4}$ & $720.31 \times 10^{-4}$ \\
\hline $\mathrm{B}$ & $10.78 \times 10^{-4}$ & $21.34 \times 10^{-4}$ & $40.99 \times 10^{-4}$ & $79.03 \times 10^{-4}$ & $89.67 \times 10^{-4}$ \\
\hline $\mathrm{C}$ & $10.67 \times 10^{-4}$ & $15.95 \times 10^{-4}$ & $25.31 \times 10^{-4}$ & $168.79 \times 10^{-4}$ & $889.69 \times 10^{-4}$ \\
\hline $\mathrm{D}$ & $2.21 \times 10^{-4}$ & $3.46 \times 10^{-4}$ & $6.79 \times 10^{-4}$ & $30.92 \times 10^{-4}$ & $72.30 \times 10^{-4}$ \\
\hline$E$ & $18.60 \times 10^{-4}$ & $29.89 \times 10^{-4}$ & $47.82 \times 10^{-4}$ & $110.24 \times 10^{-4}$ & $158.02 \times 10^{-4}$ \\
\hline $\mathrm{F}$ & $19.23 \times 10^{-4}$ & $29.42 \times 10^{-4}$ & $33.34 \times 10^{-4}$ & $46.52 \times 10^{-4}$ & $59.62 \times 10^{-4}$ \\
\hline $\mathrm{G}$ & $2.14 \times 10^{-4}$ & $3.71 \times 10^{-4}$ & $5.76 \times 10^{-4}$ & $16.96 \times 10^{-4}$ & $42.43 \times 10^{-4}$ \\
\hline
\end{tabular}


Statistically significant differences (Mann-Whitney U test) were obtained between the inside and outside of the pavilions regarding the distribution of the particles PM2.5, PM5.0 and PM10, with the air inside the pavilions more contaminated $(p=.006 ; p=.005 ; p=.005$, respectively).

\section{Discussion}

Animal confinement tends to increase the overall microbial load in the immediate production environment by virtue of the increased volumes of feed, animals, and organic residuals (manure and wastewater) present, and the increased handling and management required. Bioaerosols initially generated indoors may disperse outdoors [14].

Besides that, evidence from both epidemiological and experimental studies supports the hypothesis that exposure to fungal spores is causally associated with development of hypersensitivity pneumonitis, organic dust toxic syndrome, decline in lung function, severity of asthma, respiratory symptoms, and airway inflammation. Furthermore, a recent review document on fungal spores suggests an occupational exposure limit of $10^{5}$ spores for diverse fungal species in nonsensitized populations [15]. Epidemiological studies showed increased prevalence of respiratory symptoms and adverse changes in pulmonary function parameters in poultry workers $[16,17]$.

Regarding the fungal load in the air, indoor concentration of moulds was higher than outside air in six poultry units corroborating the possible contamination source to outdoor. However, considering only the fungal load detected indoor, a study performed in two poultry farms in Zagreb [18] presented much higher indoor counts than the ones found in the seven poultry farms analyzed in our study (published elsewhere).

In accordance with our results, also in Rimac et al. [18] species belonging to the genera Scopulariopsis, Rhizopus, Aspergillus and Penicillium were the most prevalent. Moreover, some of the most prevailing fungal species identified in our study (Penicillium and Aspergillus spp.) have been described to cause hypersensitivity reactions in humans, with clinical manifestations such as allergic rhinitis, asthma and extrinsic alveolitis [19-21].

All the seven monitored poultry farms results showed that indoor fungal species were different from the ones isolated outdoor, and six of them had more $\mathrm{cfu} / \mathrm{m}^{3}$ in indoor than outdoor air, suggesting in both situations, fungal contamination from within [22], and also, corroborating the possible indoor contamination source to outdoor.

Exposure to particulate contaminants can constitute a potential health hazard. Indoor particle concentrations involves complex combinations of numerous factors, such as emissions sources, ambient conditions, building structure and materials, work activities, ventilation and air exchange rate, which also affect particle size distributions. The results obtained in our study show the same trend that other studies developed [4, 23, 24]. In fact, we found out higher density of particles among the sizes PM5.0 and PM10. The presence of particles belonging to the respirable range $(<5-7 \mu \mathrm{m})$ shows that the found poultry dust particles can 
penetrate into the region of the lung where gas exchange occurs. Larger particles (PM10) can also cause disease by impacting in the upper and larger airways below the vocal cords.

It has also been demonstrated that dust exposure is associated with an accelerated decline in forced expiratory volume in the first second of exhalation (FEV) in farmers working in completely closed swine and poultry housing in areas of temperate climate. In these cases, and in most of the workers, the loss of FEV approximately doubles, causing a significant lung disease $[10,25]$. In a study developed by Zuskin et al. [26] measured lung function in 343 poultry farm workers, FEV and FVC (forced expiratory vital capacity) were significantly lower than the predicted. It was observed that workers exposed to the poultry house environment for more than 20 years had lower lung function than workers subjected to it during less time.

Indoor sources of particle contamination include particle generation (related for instance to combustion processes, use of spray products) and particle resuspension during intense movement [27-29]. In poultry pavilions resuspension is the most common situation, occurring with birds moving, litter spreading or turn over and other common activities related with poultry. This is well demonstrated in our study by the statistically significant differences found between the values from indoor and outdoor, indicating that activities performed inside pavilions are probably promoting particulate resuspension. Moreover, our results also reveal low or negligible outdoor influence due to the obtained results, which could be explained by the fact that normally ventilation rates are very low, particularly in the winter season, when these measurements took place. In this case, possible indoor influence on outdoor air is suggested by the same tendency obtained in indoor and outdoor: higher density of particles of bigger sizes (PM5.0 and PM10.0).

Additionally, we have to take in consideration that all poultry units studied are located in rural areas and the influence of other particles' sources from human activity was probably low.

\section{Conclusions}

The analyzed poultry units are potential reservoirs of substantial amounts of fungi and particles and could therefore free them in the atmospheric air. The developed study showed that indoor air was more contaminated than outdoors, and this can result in emission of potentially pathogenic fungi and particles via aerosols from poultry units to the outdoor environment, which may post a considerable risk to public health and environmental pollution.

\section{References}

[1] Lonc E and Plewa K: Comparison of Indoor and Outdoor Bioaerosols in Poultry Farming. Advanced Topics in Environmental Health and Air Pollution Case Studies, pp. 339-352, 2009. 
[2] Bakutis B, Monsteviliene E and Januskeviciene G: Analyses of airborne contamination with bacteria, endotoxins and dust in livestock barns and poultry houses. Acta Veterinaria Brno, 73: pp. 283-289, 2004.

[3] Oppliger A, Charrie N, Droz P and Rinsoz T: Exposure to Bioaerosols in Poultry Houses at Different Stages of Fattening; Use of Real-time PCR for Airborne Bacterial Quantification. Ann. Occup. Hyg., 52, 5: pp. 405-412, 2008.

[4] Just N, Duchaine C and Singh B: An aerobiological perspective of dust in cage-housed and floor-housed poultry operations. Journal of Occupational Medicine and Toxicology, 4:13. 2009.

[5] Kirkhorn S and Garry V: Agricultural Lung Diseases. Environmental Health Perspectives, 108 (4): pp. 50-54, 2000.

[6] Olenchock S, Lenhart S and Mull J: Occupational exposure to airborne endotoxins during poultry processing. Journal of Toxicology Environment Health, 9: pp. 339-349, 1982.

[7] Mutel C and Donham K: Occupational health problems of the rural work force. Medical Practice in Rural Communities. $1^{\text {st }}$ Ed. New York, USA: pp. 77-115, 1983.

[8] Rylander R: Lung diseases caused by organic dusts in the farm environment. American Journal of Industrial Medicine, 10: pp. 221-227, 1986.

[9] Melbostad E, Eduard W and Magnus P: Chronic bronchitis in farmers. Scandinavian Journal of Work Environment Health, pp 271-280, 1997.

[10] Iversen M, Kirychuk S, Drost H and Jacobson L: Human effects of dust exposure in animal confinement buildings. Journal of Safety Health, 1, pp. 283-238, 2000.

[11] Douwes J, Thorne P, Pearce $\mathrm{N}$ et al.: Bioaerosol health effects and exposure assessment: progress and prospects. Ann Occup Hyg., 47: pp. 187-200, 2003.

[12] Rao C, Burge $\mathrm{H}$ and Chang J., Review of quantitative standards and guidelines for fungi in indoor air. J Air Waste Manage Assoc., 46: pp. 899908, 1996.

[13] Hoog C, Guarro J, Gené G and Figueiras M., (2 ${ }^{\text {nd }}$ ed). Atlas of Clinical Fungi. Centraalbureau voor Schimmelcultures, 2000.

[14] Millner P: Bioaerosols associated with animal production operations. Bioresource Technology, 100: pp. 5379-5385, 2009.

[15] Eduard W: Fungal spores. The Nordic Group for criteria documentation of health risks from chemicals. Oslo, Norway: Arbetslivsinstitutet, 2006.

[16] Radon K, Weber C, Iversen M, Danuser B, Pedersen S and Nowak D: Exposure assessment and lung function in pig and poultry farmers. Occup Environ Med, 58: pp. 405-410, 2001.

[17] Rylander R and Carvalheiro M: Airways inflammation among workers in poultry houses. Int Arch Occup Environ Health, 79: pp. 487-490, 2006.

[18] Rimac D, Macan J, Varnai V, Vučemilo M, Matković K, Prester L, Orct T, Trošić I and Pavičic I: Exposure to poultry dust and health effects in 
poultry workers: impact of mould and mite allergens. Int Arch Occup Environ Health, 83: pp. 9-19, 2010.

[19] Halonen M, Stern D, Wright A, Taussig L and Martinez F: Alternaria as a major allergen for asthma in children raised in desert environment. Am J Respir Crit Care Med, 155: pp. 1356-1361, 1997.

[20] Ostro B, Lipsett M, Mann J, Braxton-Owens H and White M: Air pollution and exacerbation of asthma in African-American children in Los Angeles. Epidemiology, 12: pp. 200-208, 2001.

[21] Horner W, Helbling A, Salvaggio J and Lehrer S: Fungal allergens. Clin Microbiol Rev, 8: pp. 161-179, 1995.

[22] Nevalainen A., Bio-aerosols as exposure agents in indoor environment in relation to asthma and allergy. Section 3 Asthma and allergy. Proceedings of the First ENVIE Conference on Indoor Air Quality and Health for EU Policy, Helsinki, Finland, 2007.

[23] Ellen H, Bottcher R, Von Wachenfelt E and Takay H: Dust levels and control methods in poultry houses. J Agric Saf Health, 6: pp. 275-282, 2000.

[24] Donham K, Cumro D, Reynolds S and Merchand J: Dose response relationships between occupational aerosol exposures and cross-shift declines of lung function in poultry workers: recommendations for exposure limits. J Occup Environ Med, 42(3): pp. 260-9, 2000.

[25] Alencar M, Nääs I and Gontijo L: Respiratory Risks in Broiler Production Workers. Brazilian Journal of Poultry Science, 6, 1: pp. 23-29, 2004.

[26] Zuskin E, Mustajbegovic J, Schachter E Kern J, Rienzi N, Goswani S, Marom $\mathrm{Z}$ and Maayani S: Respiratory function in poultry workers: characterization of poultry dust extract. Environment Respiratory: pp. 1119, 1995.

[27] Diapouli E, Chaloulakou A and Spyrellis N: Indoor and outdoor pm concentrations at a residential environment, in the Athens area. Global NEST Journal, 10, 2: pp 201-208, 2008.

[28] Wallace L: Indoor particles: A review. Journal of the Air and Waste Management Association, 46: pp. 98-126, 1996.

[29] Nazaroff W: Indoor particle dynamics. Indoor Air, 14(7): 175-183, 2004. 